\title{
IDENTIFIKASI POTENSI AIR TANAH MENGGUNAKAN METODE RESISITIVITAS KONFIGURASI SCHLUMBERGER DI KECAMATAN BONTORAMBA KABUPATEN JENEPONTO
}

\author{
Agussalim $^{1}$ dan Andi Syam Rizal ${ }^{2}$ \\ ${ }^{1}$ Jurusan Fisika, Fakultas Matematika dan Ilmu Pengetahuan Alam, Universitas Muslim \\ Maros \\ ${ }^{2}$ Jurusan Fisika, Fakultas Sains dan Teknologi, Universitas Islam Negeri Alauddin Makassar \\ email: agussalim@umma.ac.id
}

\section{INFO ARTIKEL}

Status artikel:

Diterima: 17 Juni 2021

Disetujui: 29 Juni 2021

Tersedia online: 30 Juni 2021

Keywords: groundwater, resistivity methods, Schlumberger configuration, Res2dinv.

\begin{abstract}
Drought usually occurs, especially during the dry season in Bontoramba Sub districts, Jeneponto Regency, South Sulawesi. Therefore, it is necessary to study the potential of groundwater to meet the needs of clean water. The study was conducted to investigate the potential of groundwater both in position and depth based on the results of the interpretation of measurements. The research was done using Geo electrical Resistivity Schlumberger configuration method that gives good results vertically. The measurement points were selected through feasibility survey with a total of four measurement points. The length of the track used is a maximum of 300 meters. This research is an experimental research with a descriptive method. Data collected were analyzed and interpreted using Res2dinv software. Through the results of this interpretation, modeling of the distribution of the aquifer layer in the soil is then carried out which is projected as groundwater. The results showed that the ground water layer with resistivity value range $0-100 \Omega \mathrm{m}$. Line 1 and line 2 were on average at a depth of 10-30 m, while line 3 and line 4 at depth more than $30 \mathrm{~m}$ from the ground surface.
\end{abstract}


Agussalim dan Andi Syam Rizal / Jurnal Fisika dan Terapannya (2021) Vol. 8 (1): 36 - 43

\section{PENDAHULUAN}

Sebagian besar daerah di Kabupaten Jeneponto mengalami kekeringan khususnya pada musim kemarau. Sebanyak 113 desa dan kelurahan yang tersebar di 11 kecamatan di kabupaten Jeneponto, mengalami kekurangan air bersih termasuk masyarakat di kecamatan Bontoramba (Wakhyono, 2018). Tantangan dalam pemenuhan kebutuhan air bersih untuk masyarakat di kabupaten Jeneponto adalah rendahnya kapasitas produksi dan cakupan layanan PDAM yang baru mencapai 10,7\% (IUWASH, 2017). Masyarakat mengalami krisis air bersih karena sumur yang kering. Hal ini menyebabkan kesulitan dalam berbagai aspek kehidupan termasuk pertanian, kebutuhan air minum, dan sanitasi lingkungan.

Salah satu sumber air yang digunakan adalah groundwater (air tanah). Air tanah merupakan kumpulan dari air hujan yang meresap ke tanah dan berkumpul membentuk cekungan-cekungan tergantung dari struktur geologi dan siklus hidrologi suatu daerah. Air tanah dapat dimanfaatkan sebagai sumber air sumur pompa, sumur bor dan lain-lain (Nurfalaq dkk, 2019). Oleh karena itu, penyediaan dan pemanfaatan air tanah perlu kajian mendalam tentang potensi air tanah khususnya di daerah kecamatan Bontoramba, kabupaten Jeneponto.

Salah satu metode yang sering digunakan dalam kajian potensi air tanah adalah metode geolistrik resistivitas. Metode ini merupakan suatu metode geofisika yang memanfaatkan sifat resistivitas batuan untuk mempelajari keadaan bawah permukaan. Dalam penelitian ini digunakan metode resisivitas konfigurasi Schlumberger dengan pertimbangan konfigurasi Schlumberger mudah dan cocok dioperasikan untuk mencari potensi air tanah. Konfigurasi Schlumberger lebih efisien dan dapat memaksimalkan jumlah pasangan elektroda potensial yang diukur dengan injeksi arus sinyal sehingga jarak kedalaman yang lebih besar dapat dicapai (Widada dkk, 2017; Vasantrao dkk; 2017).

Penelitian sebelumnya untuk mengidentifikasi potensi air tanah pada lapisan bawah permukaan dengan menggunakan metode geolistrik telah dilakukan antara lain oleh Puspitasari, dkk (2019). Penelitian ini membahas tentang aplikasi metode geolistrik resistivitas untuk meneliti potensi air tanah di desa Bira, Bulukumba, Sulawesi Selatan yang termasuk daerah pesisir pantai. Penelitian oleh Santoso, dkk (2019) dan Octova, A, dkk (2019) dilakukan untuk mengkaji lapisan akuifer di daerah dengan menggunakan metode resistivitas dengan konfigurasi Schlumberger masing-masing pada daerah Tanggamus, Lampung dan Tanah Datar, Sumatera Barat. Berdasarkan berbagai hasil penelitian tersebut terlihat bahwa kondisi geologi lapisan bawah permukaan tanah dapat diprediksi dengan metode resistivitas. Daerah Bontoramba sebagai salah satu kawasan yang mengalami kekeringan selama musim kemarau belum pernah dijadikan sebagai objek penelitian identifikasi sumber air tanah. Dalam kajian yang dilakukan BAPPEDA kabupaten Jeneponto (2017) menunjukkan bahwa kecamatan Bontoramba adalah salah satu daerah yang memerlukan penambahan sumber air untuk jangka panjang. Oleh karena itu, untuk mengatisipasi kekeringan pada musim kemarau, penelitian ini dilakukan dengan mengidentifikasi potensi air tanah di kecamatan Bontoramba kabupaten Jeneponto. 


\section{METODE PENELITIAN}

Penelitian ini merupakan penelitian eksperimen dengan metode deskriptif. Lokasi penelitian dilakukan di kelurahan Bontoramba kecamatan Bontoramba kabupaten Jeneponto, Provinsi Sulawesi Selatan (Gambar 1).

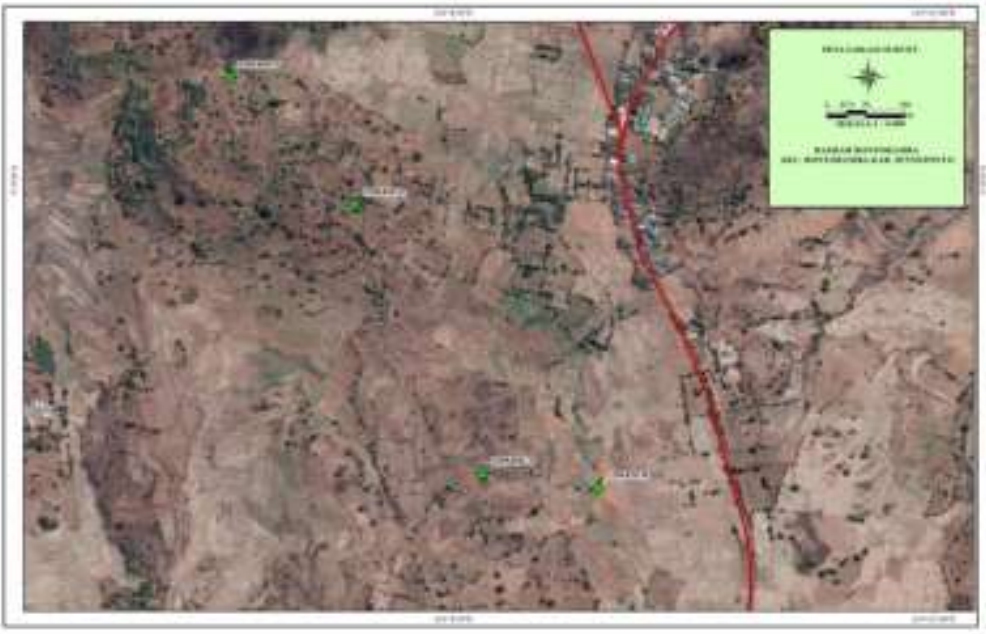

Gambar 1. Citra satelit lokasi penelitian.

Data penelitian berupa data primer dan data sekunder. Pengambilan data primer dilakukan pada tanggal 19 September 2020 dengan menggunakan metode resitivitas konfigurasi Schlumberger dengan panjang lintasan pengukuran $300 \mathrm{~m}$. Lintasan yang digunakan dalam penelitian ini sejumlah empat lintasan yang diperoleh melalui survei kelayakan lokasi sebelum penelitian dilakukan. Keempat lintasan dipilih dengan pertimbangan aksesibilitas dan posisi lokasi penelitian yang dekat dengan pemukiman masyarakat. Pengolahan data primer menggunakan software Res2div. Data sekunder yang mendukung hasil penelitian berupa peta geologi lokasi penelitian (Gambar 2).

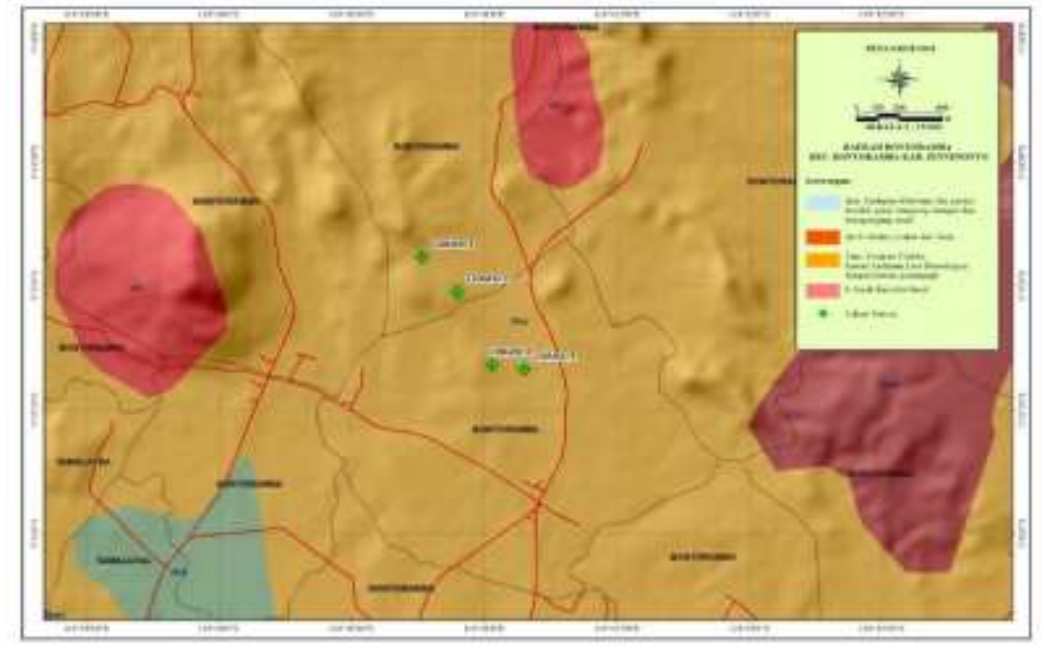

Gambar 2. Peta geologi Kecamatan Bontomaramba 
Penelitian dimulai dengan penetapan titik koordinat lokasi penelitian untuk setiap lintasan. Terdapat 4 lintasan dengan koordinat yang berbeda seperti terlihat pada Tabel 1 . Diharapkan keempat lintasan ini dapat mewakili daerah survei. Alat dan bahan yang digunakan untuk akuisisi data adalah Resistivitymeter, palu, batang elektroda, meteran, HT, kabel dan sheet data Schlumberger.

Tabel 1. Lintasan pengukuran yang diteliti

\begin{tabular}{|c|c|c|c|c|c|c|c|c|c|c|c|c|}
\hline \multirow{2}{*}{ No. } & \multicolumn{3}{|c|}{ Koordinat (S) } & \multicolumn{3}{|c|}{ Koordinat (E) } & \multirow{2}{*}{$\begin{array}{l}\text { Kondisi } \\
\text { Medan }\end{array}$} & \multirow{2}{*}{$\begin{array}{c}\text { Kondisi } \\
\text { Cuaca }\end{array}$} & \multirow{2}{*}{ Lokasi } & \multirow{2}{*}{ Tanggal } & \multirow{2}{*}{ Jam } & \multirow{2}{*}{ Formasi } \\
\hline & Derajat & Menit & Detik & Derajat & Menit & Detik & & & & & & \\
\hline 1. & 5 & 34 & 53,2 & 119 & 40 & 46,0 & Persawahan & Cerah & $\begin{array}{l}\text { Bontoramba, } \\
\text { Jeneponto }\end{array}$ & $\begin{array}{l}19 / 09 / \\
2020\end{array}$ & 09.45 & $\begin{array}{l}\text { Sedimen } \\
\text { Laut } \\
\text { Formasi } \\
\text { Camba }\end{array}$ \\
\hline 2. & 5 & 35,1 & 63,0 & 119 & 40 & 53,79 & Persawahan & Cerah & $\begin{array}{l}\text { Bontoramba, } \\
\text { Jeneponto }\end{array}$ & $\begin{array}{l}19 / 09 / \\
2020\end{array}$ & 11.55 & $\begin{array}{l}\text { Sedimen } \\
\text { Laut } \\
\text { Formasi } \\
\text { Camba }\end{array}$ \\
\hline 3. & 5 & 35 & 19,2 & 119 & 41 & 1,82 & Persawahan & Cerah & $\begin{array}{l}\text { Bontoramba, } \\
\text { Jeneponto }\end{array}$ & $\begin{array}{l}19 / 09 / \\
2020\end{array}$ & 14.46 & $\begin{array}{l}\text { Sedimen } \\
\text { Laut } \\
\text { Formasi } \\
\text { Camba }\end{array}$ \\
\hline 4. & 5 & 35 & 20,3 & 119 & 41 & 9,0 & Persawahan & Cerah & $\begin{array}{l}\text { Bontoramba, } \\
\text { Jeneponto }\end{array}$ & $\begin{array}{l}19 / 09 / \\
2020\end{array}$ & 16.07 & $\begin{array}{l}\text { Sedimen } \\
\text { Laut } \\
\text { Formasi } \\
\text { Camba }\end{array}$ \\
\hline
\end{tabular}

Proses pengambilan data dilakukan dengan memasang batang elektroda secara sejajar dalam satu garis lurus yang dihubungkan dengan resistivitymeter sehingga diperoleh nilai resistivitas semu bawah permukaan. Nilai ini kemudian diolah menggunakan Res2div untuk diinversi menjadi nilai resistivitas sebenarnya. Proses interpretasi data dilakukan untuk memperoleh citra warna yang menggambarkan distribusi resistivitas lapisan bawah permukaan. Hasil yang diperoleh merupakan dugaan lokasi dan kedalaman lapisan akuifer yang digambarkan sebagai air tanah. Kondisi lapisan akuifer hasil interpretasi data didukung hasil kajian geologi yang didasarkan pada peta geologi lokasi penelitian. Berdasarkan datadata tersebut dilakukan analisis untuk memperoleh potensi air tanah di daerah Bontoramba, kabupaten Jeneponto.

\section{HASIL DAN PEMBAHASAN}

Hasil pengukuran resistivitas yang diproyeksikan dalam penampang geologi (Gambar 3, 4, 5 dan 6) memberikan gambaran bahwa susunan litologi daerah Bontoramba Kabupaten Jeneponto. Berikut ini hasil interpretasi data dalam bentuk gambar penampang geologi daerah kajian untuk setiap lintasan. Sebagai bahan pembanding data sekunder berupa gambaran peta geologi daerah penelitan merupakan bagian dari formasi Camba yang terdiri atas batuan sedimen laut berselingan dengan batuan gunung api. 


\section{a. Lintasan 1}

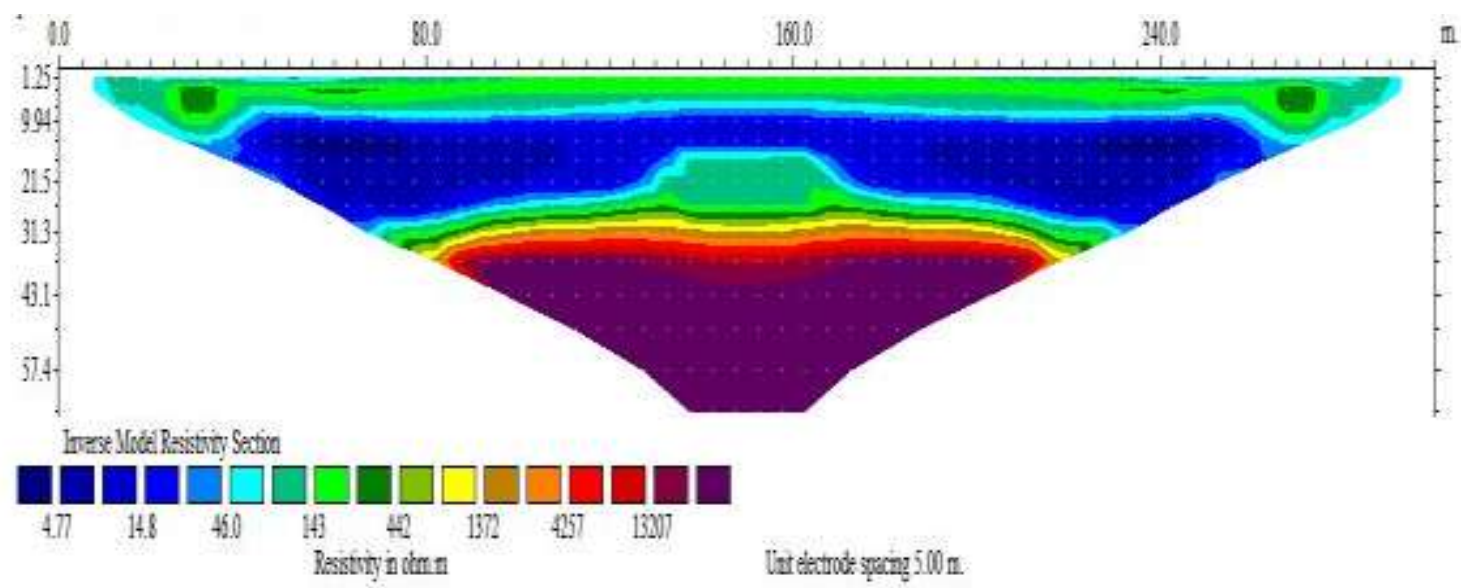

Gambar 3. Penampang Resistivitas Hasil Inversi pada Lintasan 1

Lintasan 1 dengan panjang lintasan pengukuran 300 meter kedalaman maksimal 57,4 meter. Berdasarkan hasil pengukuran diperoleh rentang nilai resistivitas semu $(\rho)$ dari lapisan tanah/batuan antara 4,77 - $13207 \Omega \mathrm{m}$. Lapisan pertama dengan nilai resistivitas antara 0 $100 \Omega \mathrm{m}$ (biru tua - biru muda) diduga terdapat air tanah dan lapisan batu gamping di atasnya dengan kedalaman 13 - $30 \mathrm{~m}$. Lapisan kedua nilai resistivitas 100 - $13207 \Omega \mathrm{m}$ (hijau - ungu) diduga merupakan lapisan batuan gunung api Formasi Camba yang kompak dan keras pada kedalaman $26-57,4 \mathrm{~m}$.

\section{b. Lintasan 2}

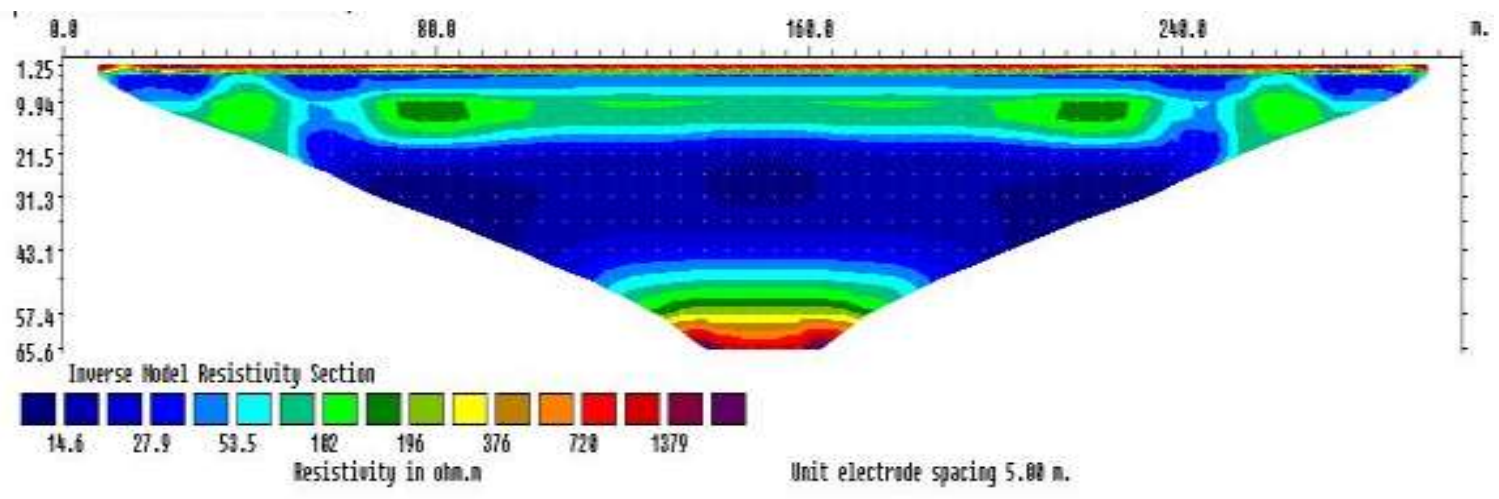

Gambar 4. Penampang Resistivitas Hasil Inversi pada Lintasan 2

Lintasan 2 dengan panjang lintasan pengukuran 300 meter kedalaman maksimal 65,6 meter. Hasil pengukuran menunjukkan rentang nilai resistivitas semu $(\rho)$ dari lapisan tanah/batuan antara 14,6 - $1279 \Omega \mathrm{m}$. Penampang resistivitas dibagi menjadi 2 bagian yaitu lapisan pertama dengan nilai resistivitas antara 0 - $100 \Omega \mathrm{m}$ (biru tua - biru muda) yang diduga terdapat air tanah dan lapisan batu gamping di atasnya dengan kedalaman 15 - 38 m. Lapisan 
kedua nilai resistivity 100 - $1279 \Omega$ m (hijau - ungu) diduga merupakan lapisan batuan gunung api Formasi Camba yang kompak dan keras pada kedalaman 39 - 65,6 m.

\section{c. Lintasan 3}

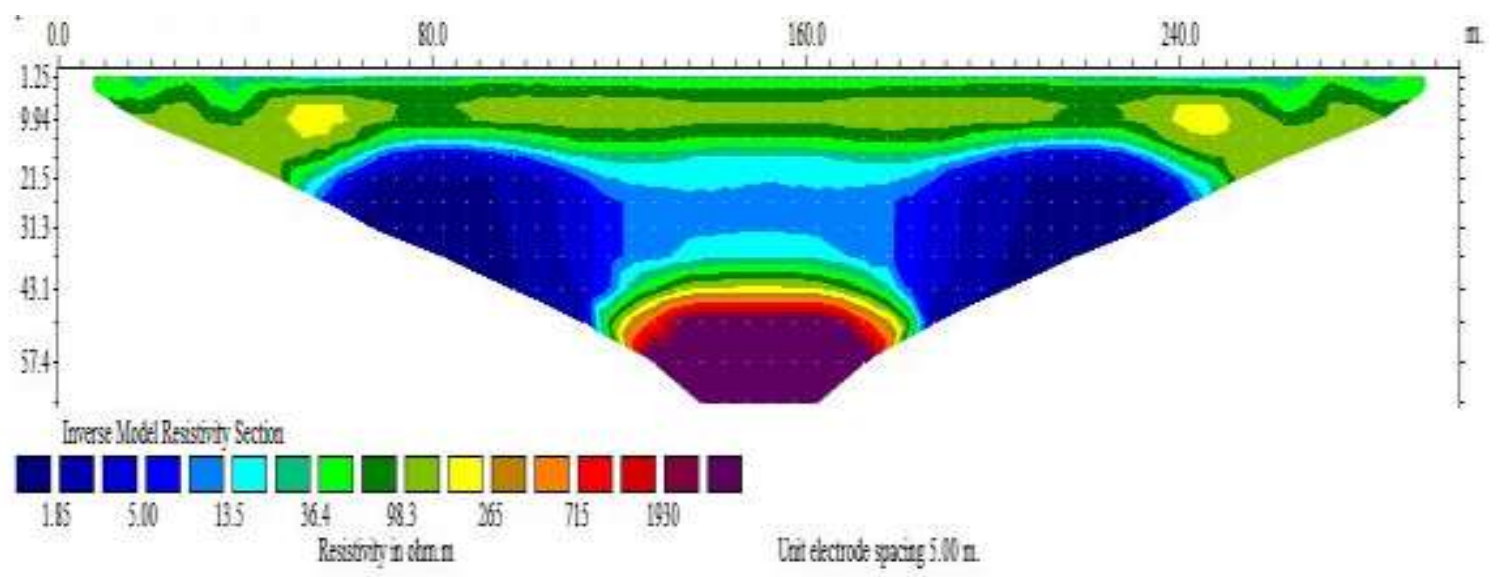

Gambar 5. Penampang Resistivitas Hasil Inversi pada Lintasan 3

Lintasan 3 dengan panjang lintasan pengukuran 300 meter kedalaman maksimal 57,4 meter. Berdasarkan hasil pengukuran diperoleh rentang nilai resistivitas semu $(\rho)$ dari lapisan tanah/batuan antara 1,85-2990 $\Omega \mathrm{m}$. Lapisan pertama dengan nilai resistivitas antara 0 - 100 $\Omega \mathrm{m}$ (biru tua - biru muda) diduga terdapat air tanah dan lapisan batu gamping di atasnya dengan kedalaman 20 - 39 m. Lapisan kedua nilai resistivity 100 - $2990 \Omega \mathrm{m}$ (hijau - ungu) diduga merupakan lapisan batuan gunung api Formasi Camba yang kompak dan keras pada kedalaman $39-57,4 \mathrm{~m}$.

\section{d. Lintasan 4}

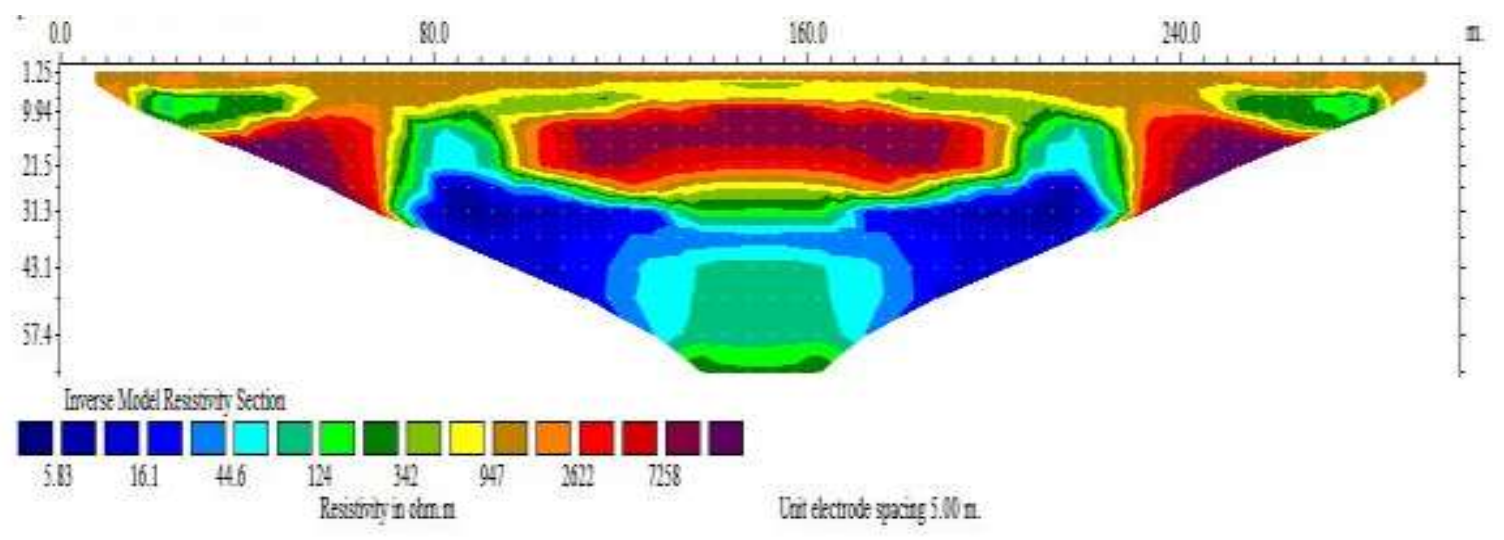

Gambar 6. Penampang Resistivitas Hasil Inversi pada Lintasan 4

Lintasan 4 dengan panjang lintasan pengukuran 300 meter kedalaman maksimal 57,4 meter. Berdasarkan hasil pengukuran didapatkan rentang nilai resistivitas semu $(\rho)$ dari 
lapisan tanah/batuan antara 5,83-7258 $\Omega \mathrm{m}$. Penampang resistivitas dibagi menjadi 2 bagian yaitu lapisan pertama dengan nilai resistivitas 100 - $2990 \Omega \mathrm{m}$ (hijau - ungu) diduga merupakan lapisan batuan gunung api dan batu gamping Formasi Camba yang kompak dan sedikit keras pada kedalaman $0-25 \mathrm{~m}$. Lapisan kedua nilai resistivitas antara $0-100 \Omega \mathrm{m}$ (biru tua - biru muda) diduga terdapat air tanah dan lapisan batu gamping diatasnya dengan kedalaman $26-43 \mathrm{~m}$.

Secara umum, hasil interpretasi data resistivitas dari daerah penelitian di kecamatan Bontoramba Kabupaten Jeneponto menunjukkan bahwa dugaan ditemukan adanya air bawah tanah baik pada lapisan akuifer dangkal maupun akuifer dalam pada daerah tersebut. Hadian dkk (2006) menjelaskan perbedaan akuifer dangkal dan akuifer dalam terletak pada kedalamannya di bawah permuaan tanah. Lapisan akuifer dangkal terletak di atas kedalaman $50 \mathrm{~m}$ bmt (di bawah permukaan tanah) dan akuifer dalam berada di bawah kedalaman $50 \mathrm{~m}$ bmt. Di antara keempat lintasan, lapisan akuifer dalam terdeteksi di lintasan 3 dan 4 dengan rata-rata kedalaman 40 meter lebih yang tertutup lapisan batuan yang bersifat keras dan kompak. Jika dimanfaatkan dengan baik maka lapisan akuifer dalam ini dapat menjadi alternatif sumber air tanah untuk mengatasi krisis air bersih di daerah penelitian. Lapisan akuifer dangkal terdeteksi pada kedalaman 10 - 30 m pada lintasan 1 dan 2. Di mana titik potensial dugaan air tanah dapat ditemukan di lintasan 2.

Berdasarkan peta geologi, lokasi penelitian (Gambar 2) termasuk formasi Camba. Dalam Rahmaniah, dkk (2020), batuan yang terdapat pada formasi Camba adalah sedimen yang terdiri atas batu pasir atau tufaan yang bersilangan dengan tufa, batu lanau dan batuan vulkanik, dari batuan-batuan inilah yang ketika mengalami pelapukan kimia maka akan membentuk tanah lempung. Hasil interpretasi berupa dugaan akuifer pada lapisan bawah permukaan lokasi penelitian dimungkinkan dari sifat batuan pada Formasi Camba seperti batuan lempung dan lanau yang memiliki porositas tinggi. Lapisan akuifer ini tertutup lapisan batuan gamping yang memiliki porositas rendah (Wiloso \& Ratmy, 2018).

\section{SIMPULAN}

Hasil interpretasi data dengan menggunakan metode geolistrik resisitivitas konfigurasi Schlumberger untuk memprediksi air tanah di Kecamatan Bontoramba Kabupaten Jeneponto menunjukkan pada lintasan 1 dan 2 terdapat lapisan yang diduga akuifer dangkal dengan kedalaman 10-30 m. sedangkan pada lintasan 3 dan 4 terdeteksi lapisan potensial akuifer dalam dengan kedalaman lebih dari $30 \mathrm{~m}$.

\section{DAFTAR PUSTAKA}

BAPPEDA Kabupaten Jeneponto. (2017). Rencana Induk Sistem Penyediaan Air Minum (RISPAM) Kabupaten Jeneponto Provinsi Sulawesi Selatan. https://sippa.ciptakarya.pu.go.id/sippa_online/ws_file/dokumen_usulan/rispam/RIS PAM_a48791d6cff7c0a58b3aac75bcb89deb8c515e5d.pdf, diakses pada 12 Juni 2021. 
Agussalim dan Andi Syam Rizal / Jurnal Fisika dan Terapannya (2021) Vol. 8 (1): 36 - 43

Hadian, M.S.D., Mardiana, U., \& Abdurahman, O. (2006). Sebaran akuifer dan pola aliran air tanah di Kecamatan Batuceper dan Kecamatan Benda Kota Tangerang, Propinsi Banten. Jurnal Geologi Indonesia, Vol. 1 No. 3 September 2006: 115-128.

IUWASH. (2017). Profil Kabupaten Jeneponto. https://www.iuwashplus.or.id/cms/wpcontent/uploads/2017/04/Profil-Kabupaten-Jeneponto.pdf, diakses pada 12 Juni 2021.

Nurfalaq, A., Nawir, A., Manrulu, R., \& Umar, E.P. (2019). Identifikasi Akuifer Daerah Pallantikang Kabupaten Jeneponto dengan Metode Geolistrik. Jurnal Fisika FLUX Volume 15, Nomor 2, Agustus 2018 ISSN : 1829-796X (print); 2514-1713(online).

Octova, A., Muji, A.S., Raeis, M., \& Putra, R.R. (2019). Identification of Aquifer using Geoelectrical Resistivity Method with Schlumberger Array in Koto Panjang Area, Nagari Tigo Jangko, Lintau Buo Sub-District, Tanah Datar Regency. The 2018 International Conference on Research and Learning of Physics IOP Conf. Series: Journal of Physics: Conf. Series 1185 (2019) 012009

Puspitasari, N. D., dkk. (2019). Subsurface Prediction Using Resistivity Method (Case study: Bira, South Sulawesi, Indonesia). Journal of Physics: Conference Series. Volume 1341, Issue 8

Rahmaniah, dkk. (2020). Analisis Mineral Tanah Rawan Longsor Menggunakan X-Ray Diffraction di Desa Sawaru Kabupaten Maros. Jambura Geoscience Review (2020) Vol. 2 (1): 41-49

Santoso, B., Prirahmayang,N., \& Kirana, K. H. (2019). Identification Of Aquifer Using Geoelectric Resistivity Method Of Reciprocal Schlumberger Array (Case Study: Tanggamus, Lampung Province) IOP Conf. Ser.: Earth Environ. Sci. 311012059

Vasantrao, B.M., Bhaskarrao, P.J. \& Mukund, B.A. (2017). Comparative study of Wenner and Schlumberger electrical resistivity method for groundwater investigation: a case study from Dhule district (M.S.), India. Appl Water Sci (2017) 7:4321-4340 https://doi.org/10.1007/s13201-017-0576-7

Wakhyono, S. (2018). "Sebelas Kecamatan di Jeneponto Krisis Air Bersih". https://fajar.co.id/2018/10/06/sebelas-kecamatan-di-jeneponto-krisis-air-bersih/ , , diakses pada 12 Juni 2021

Widada, S., Satriadi, A., \& Rochaddi, B. (2017). Kajian Potensi Air Tanah Berdasarkan Data Geolistrik Resistiviti Untuk Antisipasi Kekeringan Di Wilayah Pesisir Kangkung, Kabupaten Kendal, Privinsi Jawa Tengah. Jurnal Kelautan Tropis Maret 2017 Vol. 20(1):35-41 ISSN 0853-7291

Wiloso, D. A. \& Ratmy. (2018). Analisis Porositas Batugamping Sebagai Akuifer Di Desa Ponjong, Kecamatan Ponjong Kabupaten Gunungkidul, Daerah Istimewa Yogyakarta. Jurnal Teknologi, Volume 11, Nomor 2, Desember 2018 125-132 